\title{
Robotic urine-patch treatment and effluent application - technology to support intensification of New Zealand dairy farming while protecting the environment
}

\author{
G. BATES ${ }^{1}$ and B. F. QUIN ${ }^{2}$ \\ 1. Atelier Tech Limited, 5 Ross St, Remuera, Auckland 1050, New Zealand \\ 2. Quin Environmentals (NZ) Ltd, PO Box 125122, St Heliers, Auckland 1740, New Zealand \\ gbates@ateliertech.co.nz
}

\begin{abstract}
The need to minimise nitrate leaching and gaseous $\mathrm{N}$ losses from dairy farming is increasing; simultaneously dairy farming is undergoing rapid intensification. Robotic targeted application of nitrification and/or urease inhibitors is proposed as a route to addressing the "urine-patch" issue without risking milk contamination. This paper demonstrates a new robotic product under development and scheduled for commercial release for the 2015/2016 dairy season. The paper then discusses two developments of the product that will enable (i) highly-efficient fluidised-N application, and (ii) effluent application. These new products have the potential to greatly reduce nitrate leaching and gaseous $\mathrm{N}$ losses from dairy farming.
\end{abstract}

Keywords: robotic urine-patch treatment, nitrogen (N) losses, $\mathrm{N}$ inhibitors, effluent management, robotic effluent spreading, robotic fertiliser spreading

\section{Introduction}

New Zealand dairy exports are continuing to grow rapidly, which is good for both individual farmers and the country's economy. As more and more of the suitable land is converted from other uses to dairying, there is increasing pressure to intensify production on existing farms. This is already being seen in the massive increase in both fertiliser nitrogen $(\mathrm{N})$ use, and the import of animal feeds such as palm kernel extract (PKE) to supplement pasture production. Both lead directly to increased nitrogen deposition in urine, and the production of more effluent requiring application to the farm.

This in turn increases pressure on the ability of the land to cope with more animals without pugging and other problems developing; but most importantly, it puts a premium on the safe distribution of dairy shed effluent, minimising nutrient losses from urine patches, and minimising the survival of parasites in faecal deposition.

The increasing use of covered cow housing and stand-off/feeding pads allows collection and therefore relatively even distribution of more of the animal excreta. However, the flow-on effect of this is to increase the need to spread this material over as much of the farm as possible, meaning spreading over far higher percentages of the farm than today's typical $10-15 \%$, at an affordable cost and minimising labour requirements.

This paper describes the development of technologies which have the potential to permit increased intensification of dairy farming with significantly reduced environmental impact.

\section{Existing products and devices to reduce $\mathbf{N}$ losses from cow urine}

It has been demonstrated in several studies (Di \& Cameron 2002; Zaman \& Nguyen 2012) that treatment of the relatively small areas of pasture recently affected by urine deposition (urine patches), before the urea-N in the urine has been converted to ammonium-N and nitrate- $\mathrm{N}$, can greatly reduce total $\mathrm{N}$ losses. Because of difficulties in locating and/or treating individual patches, most existing methods have been designed to reduce losses involve treating the entire grazed pasture with $\mathrm{N}$ inhibitor(s), despite the fact that at any one time, only $2-5 \%$ of the pasture area on a farm is likely to contain urine- $\mathrm{N}$ that has not already been converted to nitrate form (Zaman \& Blennerhassett 2010). Ravensdown's Eco-N product, (a suspension of DCD in water that is sprayed onto the whole pasture by a truck and boom, with the specific objective of reducing nitrification rates of the ammonium- $\mathrm{N}$ in urine patches, and hence reducing nitrate leaching and nitrous oxide emissions), has recently been withdrawn from the market because traces of DCD are being found in milk produced by grazing the treated pastures, and in stream water. The co-granulated urea/DCD product 'DCn' marketed by Ballance has also been withdrawn from sale.

The Agri-Optic quad-bike mounted device (MacKenzie 2010) incorporates a chlorophyll detection system which enables small areas of higher pasture growth, often the result of urine deposition, to be both excluded from fertiliser $\mathrm{N}$ application, and targeted for inhibitor application. The inherent difficulties with this 

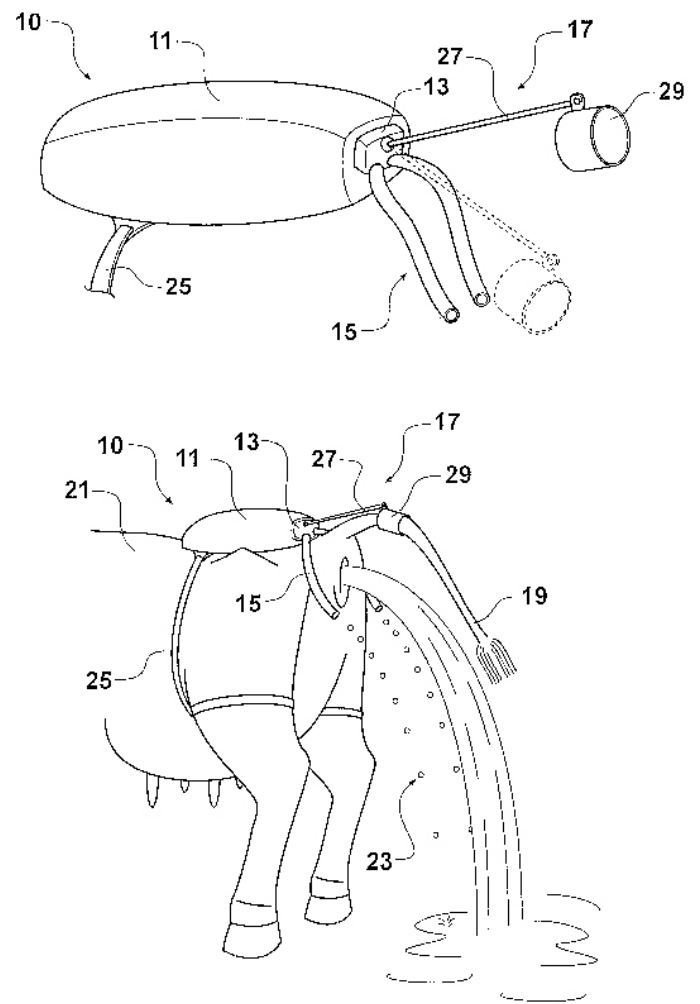

Figure 1 Schematic diagram of the Taurine device (top) and the Taurine fitted to a cow (bottom)

technology are the high labour requirement, combined with the fact that while there is extra chlorophyll present in the pasture above a urine deposition, this can mean much of the urine- $\mathrm{N}$ deposited has already been converted to nitrate form, as this is the predominant form of $\mathrm{N}$ taken up from the soil by pasture.

The Quin Environmentals patented "Taurine" device (Quin 2000) comprises an animal-mounted supply of DCD and/or the urease inhibitor NBPT in liquid, suspension or granulated forms. The action of the cow raising its tail to urinate or defecate triggers a small angle-sensitive valve on the tail to open, allowing a predetermined quantity of inhibitor to pass from the container through a tube allowing deposition in the urine patch (Figure 1). While relatively cheap to produce, this device, at least it its current iteration, suffers from higher than desirable inhibitor application variance, and refilling and maintenance involvement by farm staff. If current development work is successful in these areas, and if the device can be made more impervious to damage during bulling activity, it is likely to find a role on farms with difficult terrain.

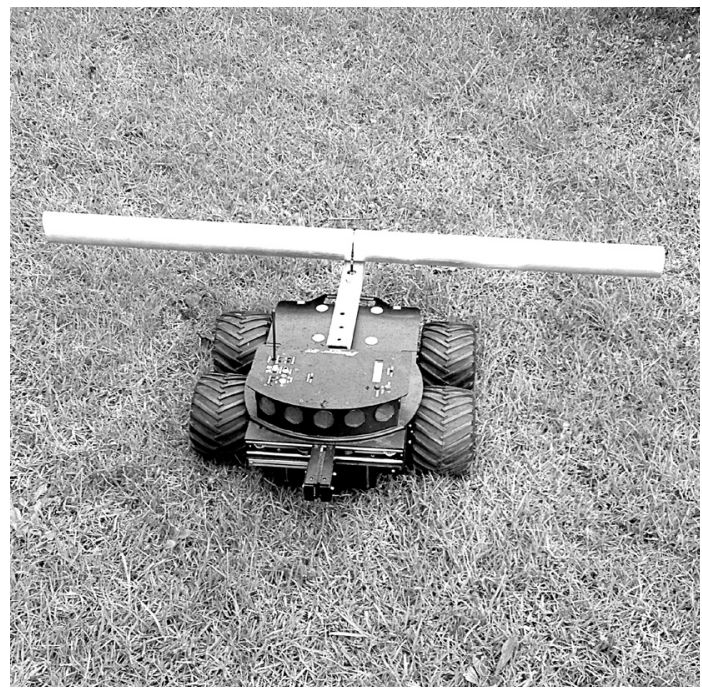

Figure 2 One-third scale development version of Mini-ME

\section{Developments to mitigate urine and effluent problems}

This paper describes three related robotically controlled vehicles designed to (i) improve the cost-effectiveness of the application of additives to treat urine, (ii) add the ability to improve the efficiency of fertiliser nutrients, and (iii) maximise the benefits of effluent application. As a consequence these devices have the potential to significantly reduce nutrient losses to the environment, while permitting considerable intensification of production.

\section{Mini-METM}

"Mini-ME" (in which ME stands for Management of Excreta) can be seen as a robotic version of the Taurine device. It is a small (approx. $1 \mathrm{~m}^{2}$ and $500 \mathrm{~mm}$ high) four-wheeled battery-powered robotically controlled vehicle with the following purposes and capabilities;

- sensing the presence of urine and dung patches through fluorescence or other techniques (patent pending)

- applying, from an on-board tank and rearmounted spray unit, a small quantity of DCD and/or urease inhibitor suspension and/or a metabolisable carbon source to these to these patches

- sensing the presence of dung and spreading it over a $2-3$ times larger area as it passes over it by means of a drag chain system or small plough attached to the front.

A working third-size 'Mini-ME' has been developed (Figure 2). It is being used to determine the most costeffective combination of basic GPS and other location and safety technologies available from Callaghan 


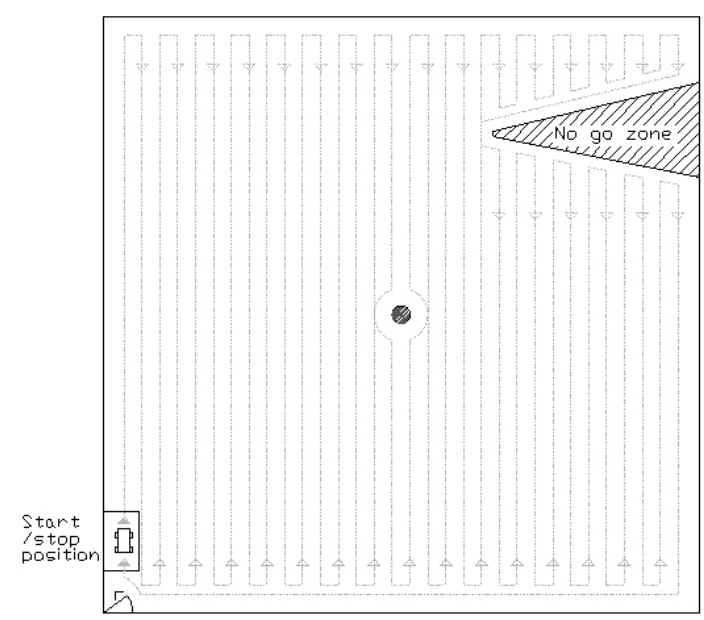

Figure 3 A representation of a predetermined path showing the start stop position and obstacles (including rough and unsuitable terrain).

Innovation, Victoria and Auckland Universities.

Assuming a $3 \mathrm{~m}$ fluorescence or other scanner controlling a $3 \mathrm{~m}$ spreading boom (which will feature individually controlled nozzles), and moving at $5 \mathrm{~km} /$ $\mathrm{hr}$, the Mini-ME would cover $1.5 \mathrm{ha} / \mathrm{hr}$. As a large herd of dairy cows (say 600-800) would normally stripgraze about 4 to $8 \mathrm{ha} /$ day, the Mini-ME will easily be able to treat the pasture grazed each day once the animals are moved off the area.

Mini-ME will require a pre-programmed farm map preloaded with routes to follow based on given start points for each paddock. The farmer will move MiniME to a new paddock daily, refilling a 20 L spray tank and swapping the batteries. Control will involve locating Mini-ME in the paddock to be treated and pushing a single go button. Each paddock will have a predetermined path for Mini-ME to follow, with a fixed start-stop point as shown in Figure 3. As Mini-ME follows its path it will scan, spray urine patches and spread cow pats as appropriate.

All the paddock maps and the driving paths for each paddock will need to be loaded into the machine on initial installation and whenever the farm boundaries, races or paddocks are changed.

Mini-ME will interface with existing products such as the TracMap system both for setup and where customers wish to record inhibitor application.

Mini-ME poses only a very low risk to humans, animals and fixed assets due to its low height and mass (less than $50 \mathrm{~kg}$ fully laden) and a low maximum ground speed ( $5 \mathrm{~km} / \mathrm{hr}$ ). Safety is ensured by using GPS technology with sufficient allowance for the location accuracy, coupled with sensors and design features to protect Mini-ME from harm. Mini-ME will be a cost

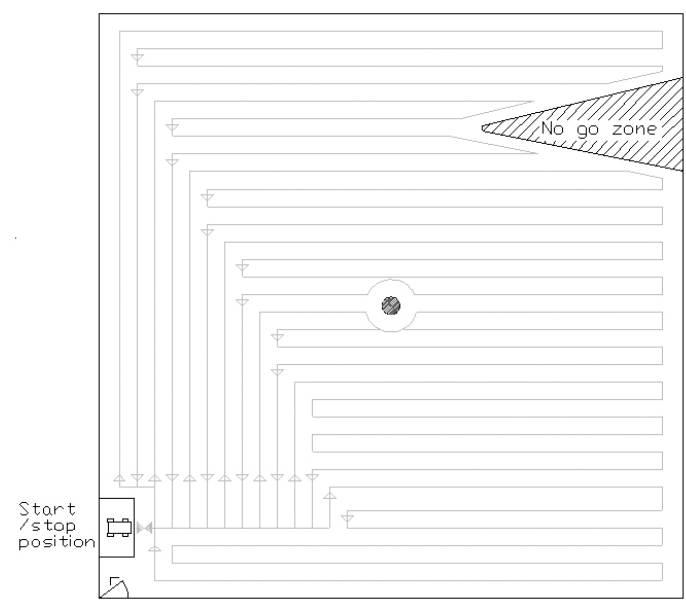

Figure 4 The more complex path plan necessary to allow Mini-ME XT to refill the urea tank.

effective medium-tech solution improving pastures, reducing nitrification rates and therefore nitrate leaching and gaseous nitrous oxide losses, and spreading dung deposits more thinly, improving nutrient recovery and reducing parasite survival periods.

\section{Mini-ME XTTM}

The addition of an extra spray tank will allow the Mini-ME base unit to apply fluidised urea (with urease inhibitor), trace elements and other additives as required. Given the extra tank, this version of Mini-ME is referred to as Mini-ME XT. Application of urea will be linked to the urine detection so that the urea delivery will cut out over urine patches. The much-improved efficiency of fluidised, urease inhibitor-treated urea allows a greater area to be treated per tank-full than would be possible with granular urea (Quin 2008; Dawar et al. 2012).

To maintain the same chassis yet be able to spread up to $50 \mathrm{~kg}$ fluidised urea per hectare $(23 \mathrm{~kg} \mathrm{~N} / \mathrm{ha})$ over 8 ha whilst avoiding additional safety requirements, Mini-ME XT will have to be able to automatically refill a urea tank of around $25 \mathrm{~L}$ up to 16 times from a holding tank of about 500 litres capacity positioned at the "startstop" position in the area to be treated (Figure 4). An example of the more complex robot path necessary to incorporate refilling is shown.

Refilling is the key technical extension between MiniME and Mini-ME XT. It adds considerable complexity and will require:

- a towable base unit with a $500 \mathrm{~L}$ tank (for an 8 ha paddock)

- fully automatic, $100 \%$ reliable docking and fluid transfer

- a method of agitating the tank

- fail-safe, spill-less transfer. 


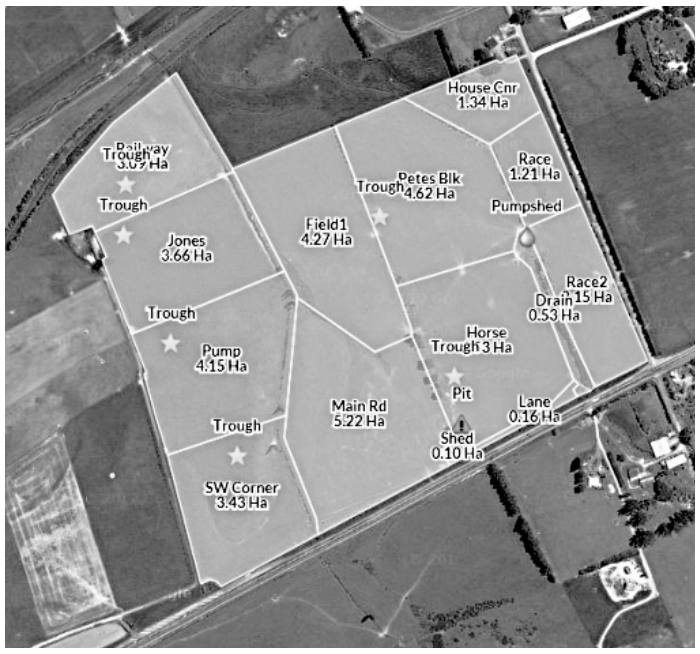

Figure 5 Typical farm view from the web based Human Machine Interface

It is important to maintain all the intelligence on Mini-ME. The robot will use Differential GPS (DGPS) for general location, and onboard sensors to locate the coupling point and guide Mini-ME XT into the refilling position. Differential GPS is an error-correcting GPS which has a fixed GPS unit at a known location, and the mobile unit is corrected for the errors measured at the fixed location. Sub-metre accuracies are possible with this technology. Whilst gravity feed has significant advantages, it would need to rely on valves, seals and active shutoff methods to ensure zero leakage, whereas the pumped system envisaged will incorporate an antisiphon design, without seals, that requires power at all times that it is transferring fluid.

The Mini-ME XT development will focus on enhancing Mini-ME to include auto refilling whilst maintaining the inherently simple pre-programmed path strategy with simple fixed start points in each paddock from which the robot automatically knows where it is and what the desired path is.

\section{Maxi-METM}

Maxi-ME is a considerably larger version of Mini-ME $\mathrm{XT}$. It retains all its abilities, but gains the advantage of being able to spread effluent and maintenance rates of NPKS fertilisers in fluidised form. The design parameters for Maxi-ME in a large dairy farm application include:

- 24 hour operation

- the need for heavier fertiliser application rates after long periods of inclement weather

- future farm intensification through the use of PKE etc.

These parameters give a tank volume in the range $3000-5000 \mathrm{~L}$. This in turn requires a vehicle of about
$2 \mathrm{~m}$ height and width, $3 \mathrm{~m}$ length, and weighing 4.5-7 tonnes when fully loaded, about half the weight of a conventional fertiliser spreading truck.

Maxi-ME will use approximately one-quarter of the energy of a comparable tractor and effluent wagon setup. This estimate takes into account that:

- the Maxi-ME is about half the weight of the conventional spreading wagon for the same daily volume and no tractor is required, bringing the total weight to approximately one-third of that of the tractor based system

- The electric drive train will be at least twice as efficient and require significantly less maintenance

- The vehicle will be operating at much lower speeds.

The logistics of a far larger vehicle moving throughout the farm rather than a single defined paddock mean that Maxi-ME will require far greater on-board intelligence and safety systems. Further, as Maxi-ME will return to a fixed point on the farm to refill with effluent, fertilisers etc., it will need a humanmachine interface so that Maxi-ME can be instructed as to which paddocks to visit etc.

The advantage of a central refilling point is that the batteries will only be required to drive the robot for one return trip (up to $30 \mathrm{~min}$ ) at which point the battery pack can be automatically swapped and recharged. This represents a significant cost saving relative to the size of the vehicle.

The key technical extensions encompassed in the step from Mini-ME XT to Maxi-ME are:

- Accuracy of location

- Safety

- Human-machine Interface.

\section{Accuracy of location}

This will be achieved through the more accurate real time kinetic (RTK) differential GPS technique and enhanced sensor fusion. Real time kinetic GPS systems use the carrier signal as the data signal, ignoring the encoded information within it. Traditional GPS aligns the signals from satellites using the binary sequence, as the signal is encoded. The difficulty in RTK systems lies in aligning the signals accurately, as every phase cycle of the carrier signal is undistinguishable. The receiver then compares its phase measurement to the phase measurement of a base station's correction signal. This technology allows users to achieve an absolute accuracy of up to $25 \mathrm{~mm}$ with tracking accuracies of 50 $\mathrm{mm}$ (Stuart 2004), however at a high cost. 


\section{Safety}

There are three critical levels of safety; people, animals and infrastructure. These are assured via a fusion of multiple design features including covering a wide range of scenarios. Safety features are both inherent and active. Inherent safety features include design features such as:

- Physical spaces which enable a person to climb onto the vehicle to avoid being crushed

- Sufficient clearance to crawl underneath the vehicle

- Design speed limits which ensure absolute maximum vehicle speeds are not above walking speeds

- Access to emergency stop buttons from all sides of the vehicle.

Active safety systems include:

- Sensors capable of detecting safety concerns at a range that is greater than the worst case braking distance

- Fusion of sensor information to ensure that accurate data is available irrespective of ambient conditions. Laser, vision, IR and sonar technologies all have optimum operating conditions and by fusing data it is possible to maximise the advantages of each technology

- Automated and repeated calibration tests

- Automated cleaning systems

- Physical barriers linked to emergency stop switches, particularly at the front and back of the vehicle

- Fail safe stop modes, for example brakes that lock on in the event of a loss of power.

- Vehicle operation within acceptable environmental conditions only. Operation during rain is not required as the spreading of fertiliser and effluent is not allowed during these conditions. On board systems can measure ambient conditions and act appropriately.

The software will include the following safety algorithms;

- If there is any animal $20 \mathrm{~m}$ in front, Maxi-ME stops until the animal has moved

- If there is any animal in the same race or paddock and within 5 metres on any side but not behind Maxi-ME, it stops

- If there is any animal within $1 \mathrm{~m}$ on all sides of Maxi-ME it stops

- No-go times can be programmed for races and other zones to avoid main periods of stock movement.

\section{Human-machine interface (HMI)}

The HMI is a web based interface that communicates with Maxi-ME. The server holds a map of the farm based on a farm survey as shown in Figure 5. The map will contain paddock, race, gate, no-go zone, path and refilling/fuelling location data, and can be updated by the user or through a service provider. The user will create action instructions as to the sequence of actions for Maxi-ME to undertake; these instructions will list the paddocks to visit in the desired order and the quantities of effluent/fertiliser etc. to be deposited. When the sequence of instructions is complete, MaxiME will return to the refill point to wait for further instructions. Whilst it will be essential that there is reception for data transfer at the refill station, the data transferred will be sufficient to allow Maxi-ME to operate fully autonomously for periods when there may not be reception during the spreading operation.

\section{Conclusions}

Technology has been developed, based on multipurpose robotic vehicles, that provides a practical solution to the Government Science Challenge of "enhancing primary sector production and productivity while maintaining and improving our land and water quality for future generations" (MBIE, 2013).

The Mini-ME and Maxi-ME products currently under development will offer a new way to manage excreta and fertiliser more efficiently. Treatment of individual urine patches, and the ability to distribute effluent very evenly over a much higher proportion of the farm than current methods, will automatically reduce nitrate- $\mathrm{N}$ leaching and gaseous $\mathrm{N}$ losses,

The authors are confident that the entry of these products into the market will help change the attitude towards effluent held by many farmers from one of "something to dispose of with as little hassle as possible", to wanting to optimise the benefits of increased pasture growth that efficient management of excreta and effluent can provide, knowing that the resulting minimisation of nutrient losses are protecting the environment.

\section{ACKNOWLEDGEMENTS}

Researchers Patrick Lim, Ray Simpkin, Kin Lung Chan and Terry Palmer of Callaghan Innovation are all part of the team developing Mini-ME and subsystems.

\section{REFERENCES}

Dawar, K.; Zaman, M.; Rowarth, J.S.; Turnbull, M.H. 2012. Applying urea with urease inhibitor (N-(nbutyl) thiophosphoric triamide) in fine particle application improves nitrogen uptake in ryegrass (Lolium perenne L.). Soil Science and Plant Nutrition 58: 309-318 
Di, H.J.; Cameron, K.C. 2002. The use of a nitrification inhibitor, dicyandiamide (DCD), to decrease nitrate leaching and nitrous oxide emissions in a simulated grazed and irrigated grassland. Soil Use and Management 18: 395-403.MacKenzie, C. H. 2010. Improvements in and relating to methods and apparatus for applying substances to an area of interest, New Zealand Patent number 582798, published 26 October 2010

MBIE. 2013. National Science Challenges, Ministry of Business Innovation and Enterprise. Accessed 26 July 2013. http://www.mbie.govt.nz/what-we-do/ national-science-challenges,

Quin, B.F. 2000. The 'Taurine' cow-mounted, tailactivated nitrogen inhibitor dispensing device. New Zealand Patent Number NZ 506883.

Quin, B.F. 2008. One-step, on-truck fluidisation and spreading of fertiliser optimises pasture response while minimising nutrient losses to the environment. pp 243-261 In: Carbon and Nutrient Management in agriculture. Eds. Currie L.D.; Yates, L.J. Occasional Report No. 21,. Fertilizer and Lime Research Centre, Massey University, Palmerston North, New Zealand

Stuart R. S. 2004. The development of an autonomous vehicle for use in agriculture. North Carolina State University Accessed: 26 July 2013. http://repository. lib.ncsu.edu/ir/bitstream/1840.16/796/1/etd.pdf

Zaman, M.; Blennerhassett, J.D. 2010. Effects of the different rates of urease and nitrification inhibitors on gaseous emissions of ammonia and nitrous oxide, nitrate leaching and pasture production from urine patches in an intensive grazed pasture system. Agriculture, Ecosystems and Environments 136: 254-261.

Zaman, M.; Nguyen, M.L. 2012. How application timings of urease and nitrification inhibitors affect $\mathrm{N}$ losses from urine patches in pastoral system. Agriculture, Ecosystems and Environments. Accessed 26 July2013. http://dx.doi.org/10.1016/j. agee.2012.04.025 